\title{
PENGARUH STRES KERJA DAN KEPUASAN KERJA TERHADAP KOMITMEN ORGANISASI KARYAWAN PBF. PT. BANYUMAS DENPASAR
}

\author{
Putu Agus Yoga Ariawan ${ }^{1}$ \\ A.A. Ayu Sriathi \\ ${ }^{1,2}$ Fakultas Ekonomi dan Bisnis Universitas Udayana, Bali, Indonesia \\ e-mail: agusyoga31@gmail.com
}

\begin{abstract}
ABSTRAK
Komitmen organisasi merupakan keterlibatan individu, perasaan memiliki dan loyalitas terhadap perusahaan atau merasa menjadi bagian dari organisasi untuk mencapai tujuan organisasi. Agar karyawan memiliki komitmen organisasi yang tinggi, suatu organisasi perlu memperhatikan faktor-faktor yang mempengaruhi komitmen organisasi seperti faktor personal, faktor organisasi dan Non-organizational faktor. Tujuan dari penelitian ini adalah untuk mengetahui pengaruh stres kerja dan kepuasan kerja terhadap komitmen organisasi karyawan di PBF. PT. Banyumas Denpasar. Penelitian ini dilakukan di PBF. PT. Banyumas Denpasar. Jumlah sampel yang diambil 35 orang karyawan, dengan metode sensus. Pengumpulan data dilakukan melalui observasi, wawancara dan kuesioner. Teknik analisis yang digunakan adalah regresi linear berganda. Berdasarkan hasil penelitian dapat disimpulkan stres kerja berpengaruh negatif dan signifikan terhadap komitmen organisasi karyawan. Hal ini menunjukkan bahwa semakin tinggi stres kerja yang dialami karyawan, maka akan semakin menurunkan komitmen organisasi. Serta kepuasan kerja berpengaruh positif dan signifikan terhadap komitmen organisasi karyawan. Hal ini menunjukkan bahwa semakin tinggi kepuasan kerja maka akan semakin tinggi pula komitmen kerja karyawan.
\end{abstract}

Kata kunci: stres kerja, kepuasan kerja, komitmen organisasi

\begin{abstract}
Organizational commitment is the involvement of individuals, feelings of belonging and loyalty to the company or feel to be part of the organization to achieve organizational goals. In order for employees to have high organizational commitment, an organization needs to pay attention to the factors that influence organizational commitment such as personal factors, organizational factors and Non-organizational factors. The purpose of this study is to determine the effect of job stress and job satisfaction on the commitment of employee organizations in the PBF. PT. Banyumas Denpasar. This research was conducted in PBF. PT. Banyumas Denpasar. Number of samples taken 35 employees, by census method. Data collection is done through observation, interview and questionnaire. The analysis technique used is multiple linear regression. Based on the results of this study, it can be concluded that work stress has a negative and significant effect on employees' organizational commitment. This shows that the higher the work stress experienced by employees, it will further decrease organizational commitment. As well as job satisfaction have a positive and significant impact on employees' organizational commitment. This shows that the higher the job satisfaction will be the higher the employee's work commitment.
\end{abstract}

Keywords: job stress, job satisfaction, organizational commitment 


\section{PENDAHULUAN}

Beragam produk yang di produksi oleh beberapa perusahaan di Indonesia membutuhkan bantuan dari pihak lain untuk menyalurkan barang produksinya ke seluruh wilayah Indonesia. Hal ini membuat perusahaan inti menunjuk beberapa perusahaan distributor pada setiap wilayah untuk menyalurkan barang produksi dari perusahaan inti tersebut. PBF (Perusahaan Besar Farmasi) PT. Banyumas merupakan salah satu perusahaan yang bergerak di bidang distributor yang berpusat di Denpasar dengan 3 cabang yaitu Denpasar, Kupang dan Mataram.

Sumber daya manusia berperan penting sebagai penggerak kegiatan operasional dalam perusahaan tersebut demi tercapainya tujuan perusahaan. Dalam beberapa kasus, masalah sumber daya manusia menjadi masalah yang sangat kompleks padahal kedudukannya menentukan kondisi perusahaan, namun sering kali dalam organisasi terjadi penurunan komitmen organisasional pada karyawan. Misalnya karyawan tidak peduli terhadap kelangsungan perusahaan, hal ini terlihat dari perilaku setiap karyawan PBF. PT. Banyumas yang hanya datang untuk bekerja tanpa memberikan masukan kepada rekan kerja atau pimpinan dan terkadang kadang mengobrol di luar pekerjaan yang sedang dijalankan (Dockel et al., 2003). Menurut Allen dan Meyer (1991) indikator yang menentukan turunnya komitmen organisasi dalam perusahaan adalah komitmen afektif, komitmen normatif dan komitmen berkelanjutan.

Menurut Mathis dan Jackson (2011: 122) komitmen organisasional adalah tingkat sampai dimana karyawan yakin dan menerima tujuan organisasi, serta berkeinginan untuk tetap menjadi bagian dari organisasi. Komitmen organisasi 
mencerminkan bagaimana seorang individu mengidentifikasikan dirinya dengan organisasi dan terikat dengan tujuan-tujuannya. Selanjutnya, komitmen yang lebih tinggi dapat mempermudah terwujudnya produktivitas yang lebih tinggi (Kreitner dan Kinicki, 2003: 274), kemajuan karir, peningkatan kompensasi serta mendapatkan imbalan intrinsik bagi individu (R.W. Rowden, 2000). Komitmen organisasional menggambarkan keterikatan seseorang di dalam organisasi, sehingga menimbulkan suatu rasa ikut memiliki (sense or belonging) terhadap organisasi tempat ia bekerja (Rahadian dan Andi, 2008). Komitmen organisasi tersebut sangat penting bagi berlangsungnya kehidupan perusahaan khususnya perusahaan PBF. PT. Banyumas, karena dapat menentukan sikap karyawan perusahaan untuk tetap mengabdikan diri pada perusahaan sehingga perusahaan bisa tetap berjalan (Yohanes dan Selly, 2004).

Streers dan Porter dalam Sopiah (2008: 164) mengemukakan ada sejumlah faktor yang mempengaruhi komitmen pegawai pada organisasi yaitu faktor personal, yang meliputi job expectation, psychological contract, job choicew factor, karakteristik personal, dan yang kedua ada faktor organisasi, yang meliputi initial works experiences, job scope, supervision, goal consistency organizational. Ketiga ada Non-organizational faktor, yang meliputi availability of alternative jobs. Berdasarkan wawancara yang dilakukan pada beberapa karyawan perusahaan PBF. PT. Banyumas, ditemukan adanya fenomena mengenai adanya indikasi mengenai komitmen yang rendah dalam perusahaan seperti kurangnya tanggung jawab dalam menyelesaikan tugas, adanya keinginan untuk keluar dari organisasi tetapi mereka tidak melakukannya karena keterbatasan pendidikan. 
Selain faktor di atas yang sudah dijelaskan, faktor lain yang menyebabkan turunnya komitmen organisasi adalah stres kerja (Gede dan Agoes, 2016). Stres merupakan bidang perhatian bagi pengusaha dan karyawan sebagai bagian dari organisasi, stres menentukan optimal atau tidaknya keluaran karyawan dan membuat pekerjaan karyawan tersebut berarti bagi mereka (Hlatywayoet al., 2014; Uppalet al., 2014). Stres kerja bertindak sebagai tantangan besar dan ancaman psikologis, fisik individu serta kesehatan organisasi. Stres menyebabkan banyak masalah (Yahaya et al., 2010; Hlatywayo et al., 2014), karena itu stres penting untuk ditanggulangi untuk meningkatkan kehidupan, kesehatan dan produktifitas karyawan (Siagian, 2012:140). Gejala stress yang berdampak negatif bagi perusahaan termasuk ke dalam distress, karena sering kali menghasilkan perilaku karyawan yang disfungsional seperti sering melakukan kesalahan, moral yang rendah, bersikap masa bodoh dan absen tanpa alasan. Di sisi lain stress juga bisa berdampak positif terhadap karyawan atau disebut juga sebagai eusstress yang bisa menimbulkan efek menciptakan tantangan dan perasaan untuk bisa selalu berprestasi serta berperan sebagai faktor motivator yang kritis bagi banyak karyawan (Indra dan Eko, 2013).

Salah satu masalah dari stres seperti tuntutan pekerjaan yang tidak sesuai dan tugas tidak sesuai wewenang jabatan bisa berpengaruh ke komitmen organisasi yang menyebabkan komitmen organisasi tersebut menjadi rendah, efek berlebihan dari stres ini adalah meningkatkan niat karyawan untuk keluar dari organisasi dan kinerja organisasi berkurang (Cicei, 2012; Gayathiri \& Ramakrishnan, 2014). Berdasarkan hasil wawancara dengan beberapa karyawan 
PBF. PT. Banyumas mengenai indikasi tentang stres kerja ditemukan fenomena bahwa karyawan menerima tuntutan pekerjaan yang terlalu besar sehingga ada pekerjaan yang selesai tetapi tidak tepat waktu. Hal ini menyebabkan karyawan stres karena tidak bisa memenuhi kewajibannya sebagai karyawan.

Berdasarkan latar belakang masalah, maka dapat dirumuskan pokok masalah yaitu, Bagaimana pengaruh stres kerja terhadap komitmen organisasi karyawan PBF. PT. Banyumas, dan Bagaimana pengaruh kepuasan kerja terhadap komitmen organisasi karyawan PBF. PT. Banyumas. Berdasarkam rumusan masalah di atas, maka tujuan dari penelitian ini adalah Menganalisis pengaruh stres kerja terhadap komitmen organisasi karyawan PBF. PT. Banyumas. Menganalisis pengaruh kepuasan kerja terhadap komitmen organisasi karyawan PBF. PT. Banyumas.

Khatibi et al. (2009) dan Firth et al. (2004) menyatakan ada hubungan negatif antara stres kerja dengan komitmen organisasi, pegawai yang memiliki tingkat stres tinggi berimplikasi terhadap rendahnya komitmen organisasi mereka. Begitu juga dengan Velnampy dan Aravinthan (2013) yang menyatakan adanya hubungan negatif antara stres kerja dan komitmen organisasi. Moncrief et al. (1997) berpendapat adanya pengaruh signifikan dan negatif stres kerja dan komiten organisasi yang sangat berpengaruh terhadap kelangsungan organisasi. Peran konflik dan peran ambigius sebagai pembentuk stres mempunyai pengaruh terhadap penurunan komitmen organisasi yang artinya terdapat hubungan yang negatif dan signifikan antara stres kerja dengan komitmen organisasi (Pool, 2000). Cha et al. (2011) mengungkapkan stres kerja memiliki hubungan yang signifikan 
dan negatif dengan komitmen organisasi. Stres kerja berpengaruh negatif pada komitmen organisasi karena semakin tinggi stres mengakibatkan semakin menurunnya komitmen organisasi. (Iresa dkk., 2015). Dari uraian tersebut, maka dapat dikemukakan hipotesis sebagai berikut :

$\mathrm{H}_{1} \quad$ : Stres kerja berpengaruh negatif terhadap Komitmen Organisasi

Koh dan Bo (2004) menyatakan kepuasan kerja karyawan berpengaruh positif terhadap komitmen organisasi. Begitu juga dengan Eslami dan Gharakhani (2012) yang menyatakan karyawan yang memiliki kepuasan kerja cenderung berkomitmen untuk organisasi dan karyawan yang puas dan berkomitmen lebih mungkin untuk menghadiri pekerjaan. Lumley (2011) menyimpulkan kepuasan kerja mempengaruhi sikap masyarakat terhadap pekerjaan dan berbagai aspek pekerjaan mereka, kepuasan kerja dipengaruhi oleh pribadi yang menyebabkan reaksi emosional yang mempengaruhi komitmen organisasi.

Oyewobi et al. (2012) pada penelitian quantity surveyor dalam pelayanan publik nigeria menunjukan bahwa ada korelasi positif antara variabel kepuasan kerja dengan komitmen organisasi. Adekola (2012) menunjukan hasil analisis regresi linear berganda yang berhubungan positif antara kepuasan kerja dengan komitmen organisasi. Pradhiptya (2013) meyatakan bahwa kepuasan kerja berpengaruh positif dan signifikan terhadap komitnmen organisasi.Hasil yang sama juga dinyatakan dalam penelitian yang dilakukan oleh Tania dan Sutanto (2013) bahwa kepuasan kerja memiliki pengaruh positif dan signifikan terhadap komitmen organisasional. 
Putu Agus Yoga Ariawan dan A.A. Ayu Sriathi. Pengaruh Stres Kerja...

Penelitian ini mendukung penelitian DeConmick dan Will dalam Widyanti dkk. (2004) yang menemukan bahwa kepuasan kerja merupakan suatu prediktor yang signifikan terhadap komitmen karyawan pada organisasi. Silvia (2006) menyatakan bahwa kepuasan berpengaruh positif dan signifikan terhadap komitmen. Yousef (2002) juga menyatakan bahwa kepuasan kerja berpengaruh positif dan signifikan terhadap komitmen. Ramayah dan Nasurdin (2003) dalam penelitiannya menunjukkan bahwa kepuasan kerja yang digambarkan pada kepuasan gaji, promosi, supervisi dan kerjasama antar pekerja sangat besar pengaruhnya dalam menentukan komitmen pekerja terhadap organisasi. Ini berarti bahwa semakin tinggi kepuasan kerja yang dirasakan oleh karyawan, maka semakin termotivasi pula karyawan dalam peningkatan komitmen organisasinya dan sebaliknya, semakin rendah kepuasan kerja yang yang dirasakan oleh karyawan, maka semakin karyawan tidak termotivasi untuk meningkatkan komitmen organisasinya (Dana Pramitha dkk., 2010). Dari uraian tersebut dapat dikemukakan hipotesis sebagai berikut :

$\mathrm{H}_{2}$ : Kepuasan kerja berpengaruh positif terhadap Komitmen Organisasi

Berdasarkan penelusuran kajian pustaka dan hasil hasil penelitian sebelumnya maka model konseptual penelitian ini dapat dilihat pada gambar 1 sebagai berikut. 


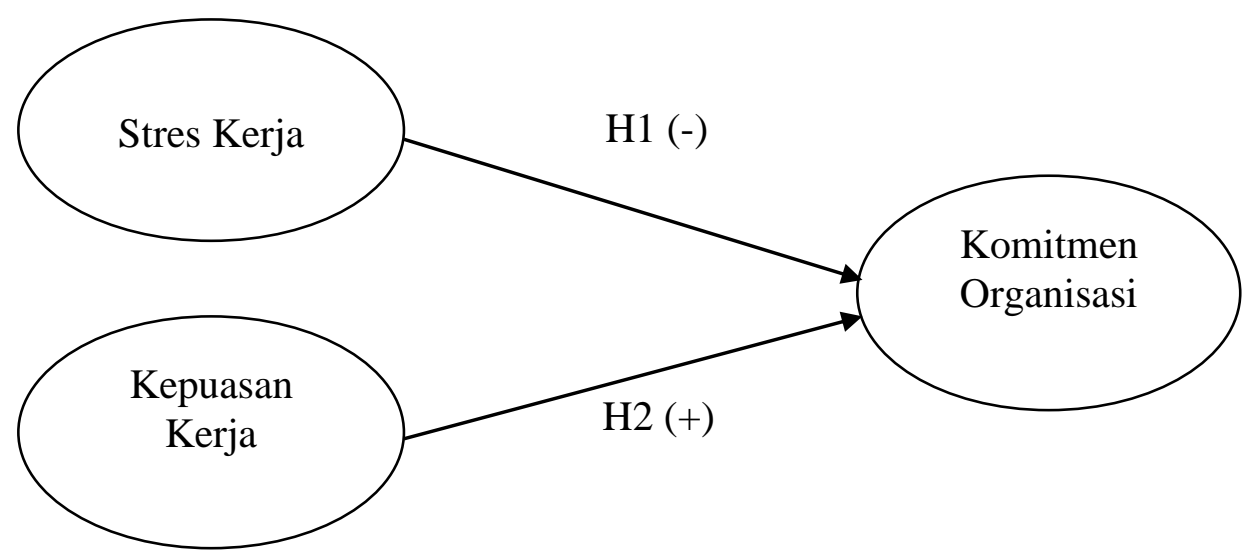

\section{Gambar 1. Model Konseptual Penelitian}

Sumber:

$\mathrm{H}_{1} \quad$ : Khatibi et al. (2009), Firth et al. (2004), Velnampy dan Aravinthan (2013), Moncrief et al. (1997), Pool (2000), Cha et al. (2011), Iresa dkk. (2015).

$\mathrm{H}_{2} \quad$ : Koh dan Bo (2004), Eslami dan Gharakhani (2012), Lumley (2011), Oyewobi et al. (2012), Adekola (2012), Pradhiptya (2013), Tania dan Sutanto (2013), Widyanti dkk. (2004), Silvia (2006), Yousef (2002).

Dana Pramitha dkk. (2010).

\section{METODE PENELITIAN}

Berdasarkan permasalahan yang diteliti, penelitian yang digolongkan pada penelitian asosiatif (hubungan), yaitu penelitian yang bertujuan untuk mengetahui pengaruh dari satu variabel, dua variabel atau lebih. Metode ini digunakan untuk mengetahui hubungan antara variabel stres kerja dan kepuasan kerja terhadap komitmen organisasional.

Lokasi penelitian ini dilakukan di PBF. PT. Banyumas yang beralamat di Jalan Kepundung No.70 Denpasar. Lokasi ini dipilih karena adanya indikasi komitmen yang rendah berdasarkan hasil observasi peneliti. Subjek dari penelitian ini adalah seluruh karyawan PBF. PT. Banyumas Denpasar. Obyek penelitian ini, yaitu stres kerja, kepuasan kerja, dan komitmen organisasional.

Variabel-variabel yang diidentifikasi dalam penelitian ini dapat dikelompokan menjadi dua jenis, yaitu Variabel terikat (dependent variable) 
merupakan variabel yang tergantung dari variabel lain. Variabel terikat dalam penelitian ini adalah komitmen organisasi. Variabel bebas (independent variable) merupakan variabel yang dapat mempengaruhi variabel lain. Variabel bebas dalam penelitian ini adalah stres kerja dan kepuasan kerja.

Jenis data yang digunakan dalam penelitian ini adalah data kuantitatif dan data kualitatif. Data kualitatif adalah data yang dinyatakan dalam bentuk kata, kalimat dan gambar. Data kualitatif dalam penelitian ini berupa pendapat dari responden yang meliputi variabel stres kerja, kepuasan kerja, komitmen organisasional. Data kuantitatif adalah data yang berupa angka - angka atau data kualitatif yang diangkakan. Data kuantitatif dalam penelitian ini adalah data karyawan pada perusahaan PBF. PT. Banyumas. Sumber data yang digunakan dalam penelitian ini dimana sumber primer dan sumber sekunder. Sumber primer, responden yang langsung memberikan jawaban atau skor terhadap variabelvariabel penelitian yang terdapat dalam kuisioner. Sumber sekunder, data yang didapat dari sumber - sumber yang sudah tersedia seperti dari data perusahaan, sejarah perusahaan.

Sugiyono (2014:115) menyatakan populasi adalah wilayah generalisasi yang terdiri atas obyek/subyek yang mempunyai kualitas dan karakteristik tertentu yang ditetapkan oleh peneliti untuk dipelajari dan kemudian ditarik kesimpulannya. Dalam penelitian ini yang menjadi populasi adalah seluruh karyawan perusahaan PBF. PT. Banyumas. Ukuran populasi penelitian ini sejumlah 35 orang karyawan, sedangkan pimpinan PBF. PT. Banyumas tidak termasuk dalam responden 
penelitian karena pimpinan organisasi sudah memiliki komitmen tinggi untuk menjalankan perusahaan demi tercapainya tujuan perusahaan (Humala, 2014).

Adapun metode pengumpulan data dilakukan dengan cara observasi, wawancara dan kuesioner. Metode observasi yaitu metode pengumpulan data dengan mengadakan pengamatan secara langsung ke PBF. PT. Banyumas tentang obyek yang diteliti serta melakukan pencatatan secara sistematis untuk mengamati kinerja pegawai. Metode wawancara merupakan metode pengumpulan data dengan cara tanya jawab masalah yang akan diteliti. Pertanyaan yang diajukan seperti permasalahan mengenai stres kerja, kepuasan kerja dan komitmen organisasi pegawai kantor PBF. PT. Banyumas. Metode Kuesioner adalah metode pengumpulan data dengan menggunakan daftar pertanyaan yang disebarkan kepada responden mengenai stres kerja, kepuasan kerja terhadap komitmen organisasi pegawai kantor PBF. PT. Banyumas.

Skala pengukuran data merupakan kesepakatan yang digunakan sebagai acuan untuk menentukan panjang pendeknya interval yang ada dalam ukuran (dalam hal kuesioner), sehingga alat ukur tersebut bila dilakukan dalam pengukuran menghasilkan data kuantitatif. Penilaian untuk variabel stres kerja, kepuasan kerja dan komitmen organisasi menggunakan satu skala yaitu Skala Likert dengan skala 1-5. Skala likert digunakan untuk mengukur sikap, pendapatan dan persepsi seseorang atau sekelompok orang mengenai fenomena sosial. Jawaban dari setiap item instrument yang menggunakan skala likert memiliki gradasi jawaban dari sangat positif atau sangat negatif. 
Pada penelitian ini kesungguhan responden dalam menjawab pernyataan merupakan hal yang paling penting dikarenakan keabsahan (validitas) suatu hasil penelitian sangat tergantung oleh alat pengukur instrumen yang digunakan dan data yang diperoleh. Berdasarkan pertimbangan tersebut, dalam penelitian ini teknik analisis data diawali dengan pengujian instrumen yaitu dengan menguji validitas dan reliabilitas instrumen sehingga dapat diketahui apakah jawaban responden tersebut telah dijawab dengan benar atau tidak.

Uji hipotesis melalui analisis regresi linier berganda yaitu model regresi yang melibatkan satu atau lebih variabel terikat (Y) dengan dua atau lebih variabel bebas (X1,X2,X3_....Xn) (Wirawan, 2002:292). Rumus model regresi linier berganda yang digunakan yaitu sebagai berikut.

$Y=\alpha+\beta_{1} X_{1}+\beta_{2} X_{2}$

Keterangan :

$\begin{array}{ll}\mathrm{Y} & =\text { Komitmen Organisasi } \\ \alpha & =\text { Konstanta } \\ \beta_{1} \cdot \beta_{2} & =\text { Koefisien regresi variabel } \mathrm{X}_{1} . \mathrm{X}_{2} \\ \mathrm{X}_{1} & =\text { Stres Kerja } \\ \mathrm{X}_{2} & =\text { Kepuasan Kerja }\end{array}$

Penggunaan analisis ini karena mampu menginterpretasikan dan menjelaskan hubungan linier antara stres kerja, kepuasan kerja dan komitmen organisasi karyawan.

Pengujian hipotesis dapat dilakukan apabila model regresi linier berganda sudah memenuhi syarat uji asumsi klasik. Uji asumsi klasik yang dilakukan terhadap penelitian adalah dengan uji normalitas, uji multikolinearitas dan uji heteroskedastisitas. 


\section{HASIL DAN PEMBAHASAN}

Responden dari penelitian ini di gambarkan secara umum dengan menyajikan karakteristik yang di lihat dari beberapa variable demografi yaitu nama, usia, jabatan, jenis kelamin dan pendidikan terakhir. Jumlah responden yang di gunakan dalam penelitian ini sebanyak 35 orang responden.

Karakteristik Berdasarkan Jenis Kelamin, Kriteria jenis kelamin responden dapat digunakan sebagai acuan untuk mengetahui proporsi responden laki-laki dan perempuan. Berdasarkan data dapat dilihat bahwa responden yang berjenis kelamin laki-laki berjumlah 26 responden atau sekitar 74,2 persen dan responden yang berjenis kelamin perempuan berjumlah 9 responden atau sekitar 24,8 persen.

Karakteristik Berdasarkan Usia, Data menunjukkan bahwa karyawan PBF. PT. Banyumas sebagian besar berumur 31 tahun ke atas dengan jumlah sebanyak 17 orang atau berkisar 49 persen. Artinya semakin tinggi persaingan di dunia kerja menyebabkan karyawan akan memiliki komitmen dengan organisasinya.

Karakteristik Berdasarkan Jabatan, Data menunjukan bahwa jabatan yang paling banyak dipegang pegawai adalah salesman yaitu sebanyak 7 orang atau berkisar 20 persen. Artinya pendapatan perusahaan tergantung pada penjualan yang dilakukan oleh salesman perusahaan yang berarti para salesman ini harus memiliki komitmen tinggi dalam pekerjaannya, karena pendapatan yang di dapat perusahaan tergantung pada pemasaran yang dilakukan oleh salesman yang bertugas dalam perusahaan tersebut.

Karakteristik Berdasarkan Pendidikan Terakhir, Data menunjukan bahwa pendidikan terakhir dari para pegawai PT. Banyumas sebagian besar adalah 
Putu Agus Yoga Ariawan dan A.A. Ayu Sriathi. Pengaruh Stres Kerja...

lulusan SMA yaitu dengan persentase sebesar 26 orang atau 74 persen, untuk diploma 2 dan 3 masing - masing sebesar 6 persen atau 2 orang, dan S1 sebesar 5 orang atau sekitar 14 persen. Ini berarti tingkat pendidikan karyawan PBF. PT. Banyumas sudah cukup baik.

Uji validitas dapat dilakukan dengan mengkorelasikan antar skor item instrument dengan skor total seluruh item pertanyaan. Jika korelasi antara masing - masing skor butir pertanyaan terhadap toal skor butir - butir pertanyaan menunjukkan nilai koefisien korelasinya $\geq 0,3$ maka masing-masing butir pernyataan tersebut dikatakan valid (Sugiyono, 2012:178).

Tabel 1.

Hasil Uji Validitas Instrumen

\begin{tabular}{ccccc}
\hline No & Variabel & Indikator & $\begin{array}{c}\text { Koefisien } \\
\text { Korelasi }\end{array}$ & Keterangan \\
\hline \multirow{3}{*}{1} & \multirow{2}{*}{ Stres Kerja } & X1.1 & 0,912 & Valid \\
& & X1.2 & 0,96 & Valid \\
2 & Kepuasan Kerja & X1.3 & 0,959 & Valid \\
& & X2.1 & 0,869 & Valid \\
& & X2.2 & 0,807 & Valid \\
& & X2.3 & 0,88 & Valid \\
& & X2.5 & 0,772 & Valid \\
& & X2.6 & 0,817 & Valid \\
& & X2.7 & 0,871 & Valid \\
& & Y1.1 & 0,899 & Valid \\
3 & Komitmen & Y1.2 & 0,85 & Valid \\
& Organisasi & Y1.3 & 0,889 & Valid \\
& & & 0,937 & Valid \\
\hline
\end{tabular}

Sumber: Data Diolah, 2017

Hasil uji validitas yang ditampilkan pada tabel 1 menunjukan bahwa 13 indikator yang digunakan memiliki nilai korelasi di atas 0,3 yaitu nilai korelasi terkecil 0,772 hingga nilai korelasi yang terbesar sebesar 0,960 sehingga keseluruhan indikator yang digunakan dinyatakan valid dan dapat dilanjutkan ke analisa berikutnya. 
Selain harus dikatakan valid, instrumen yang digunakan untuk mengukur variabel yang diteliti juga harus dikatakan reliabel sehingga layak untuk digunakan mengumpulkan data. Instrumen yang reliabel adalah instrumen yang memiliki nilai Cronbach's Alpha lebih besar dari 0,60 sehingga korelasi tersebut signifikan dan instrument tersebut dapat digunakan (Sugiyono, 2012:172).

Tabel 2.

Hasil Uji Reliabilitas

\begin{tabular}{lcc}
\hline \multicolumn{1}{c}{ Variabel } & Alpha Cronbach & Keterangan \\
\hline Stres Kerja & 0,936 & Reliabel \\
Kepuasan Kerja & 0,928 & Reliabel \\
Komitmen Organisasi & 0,872 & Reliabel \\
\hline Sumber: Data Diolah, 2017 & &
\end{tabular}

Hasil uji reliabilitas yang ditampilkan pada tabel 2 menunjukan seluruh instrumen penelitian dikatakan reliabel sehingga dapat digunakan untuk mengumpulkan data. Nilai keseluruhan alpha cronbach $\geq 0,6$ menunjukan bahwa pengukuran tersebut dapat memberikan hasil yang konsisten apabila dilakukan pengukuran kembali terhadap subjek yang sama pada waktu yang berbeda.

Tabel 3 menunjukkan bahwa skor untuk variabel stres kerja adalah sebesar 2,84 ini berarti bahwa responden menyatakan cukup setuju pada variabel stres kerja pada perusahaan PBF. PT. Banyumas. Hal ini diperinci sebagai berikut. Responden menyatakan setuju untuk pernyataan tuntutan yang tidak sesuai dengan kemampuan (x1.1), melakukan tugas tidak sesuai dengan wewenang jabatan (x1.2), kepala perusahaan yang tidak mendukung pekerjaan yang dilakukan (x1.3). 
Tabel 3.

Deskripsi Persepsi Responden Terhadap Variabel Stres Kerja

\begin{tabular}{|c|c|c|c|c|c|c|c|c|}
\hline \multirow{2}{*}{ No } & \multirow{2}{*}{ Pernyataan } & \multicolumn{5}{|c|}{ Proporsi Jawaban Responden } & \multirow{2}{*}{$\begin{array}{c}\text { Rata- } \\
\text { Rata }\end{array}$} & \multirow{2}{*}{ Kriteria } \\
\hline & & STS & TS & $\mathbf{N}$ & $\mathbf{S}$ & SS & & \\
\hline 1 & $\begin{array}{l}\text { Tuntutan pekerjaan saya } \\
\text { tidak sesuai dengan } \\
\text { kemampuan saya dalam } \\
\text { menyelesaikan tugas. }\end{array}$ & 2 & 11 & 11 & 9 & 2 & 2,94 & $\begin{array}{l}\text { Cukup } \\
\text { Tinggi }\end{array}$ \\
\hline 2 & $\begin{array}{l}\text { Saya melakukan tugas } \\
\text { tidak sesuai dengan } \\
\text { wewenang jabatan saya. } \\
\text { Kepala perusahaan saya }\end{array}$ & 1 & 18 & 4 & 12 & 0 & 2,77 & $\begin{array}{l}\text { Cukup } \\
\text { Tinggi }\end{array}$ \\
\hline 3 & 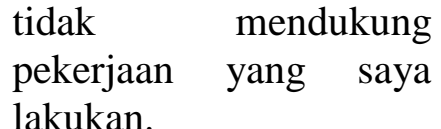 & 2 & 18 & 2 & 11 & 2 & 2,80 & $\begin{array}{l}\text { Cukup } \\
\text { Tinggi }\end{array}$ \\
\hline \multicolumn{7}{|c|}{ Stres Kerja } & 2,84 & $\begin{array}{l}\text { Cukup } \\
\text { Tinggi }\end{array}$ \\
\hline
\end{tabular}

Sumber: Data Diolah, 2017

Dari Tabel 3 dapat disimpulkan variabel stres kerja secara keseluruhan memiliki nilai rata - rata 2,84 yang berarti stres kerja yang dialami pegawai tergolong cukup Tinggi. Hal ini dapat dilihat dari masing - masing nilai indikator yang berada antara nilai interval cukup buruk. Hal ini berarti tuntutan pekerjaan, tugas dan wewenang karyawan yang tidak sesuai, dukungan kepala perusahaan perlu adanya perhatian lebih dari kepala perusahaan untuk mengurangi stres kerja yang dialami pegawai.

Tabel 4 menunjukkan bahwa skor untuk variabel kepuasan kerja adalah sebesar 3,76 ini berarti menyatakan bahwa responden setuju pada variabel kepuasan kerja pada perusahaan PBF. PT Banyumas. Hal ini dapat diperinci sebagai berikut : pekerjaan yang dilakukan sangat menarik (x.2.1), merasa nyaman saat bekerja pada perusahaan (x.2.2), mampu menunjukkan prestasi dalam perusahaan (x.2.3), diberi kesempatan berupa promosi jabatan (x.2.4), 
diberi penghargaan atas prestasi yang diraih (x.2.5), mampu menyelesaikan tugas sesuai wewenang (x.2.6), mampu menerima arahan dari pimpinan dan jabatan yang lebih tinggi (x.2.7).

Tabel 4.

Penilaian Responden pada Variabel Kepuasan Kerja

\begin{tabular}{|c|c|c|c|c|c|c|c|c|}
\hline \multirow[t]{2}{*}{ No } & \multirow[t]{2}{*}{ Pernyataan } & \multicolumn{5}{|c|}{$\begin{array}{l}\text { Proporsi Jawaban } \\
\text { Responden }\end{array}$} & \multirow{2}{*}{$\begin{array}{l}\text { Rata- } \\
\text { Rata }\end{array}$} & \multirow[t]{2}{*}{ Kriteria } \\
\hline & & STS & TS & $\mathbf{N}$ & $\mathbf{S}$ & SS & & \\
\hline 1 & $\begin{array}{l}\text { Saya merasa pekerjaan yang } \\
\text { saya lakukan sangat menarik. }\end{array}$ & 0 & 3 & 11 & 20 & 1 & 3,54 & Puas \\
\hline 2 & $\begin{array}{l}\text { Saya merasa nyaman bekerja } \\
\text { dalam perusahaan. }\end{array}$ & 0 & 2 & 8 & 18 & 7 & 3,86 & Puas \\
\hline 3 & $\begin{array}{l}\text { Saya mampu menunjukan } \\
\text { prestasi kerja dalam } \\
\text { perusahaan. }\end{array}$ & 0 & 2 & 7 & 16 & 10 & 3,97 & Puas \\
\hline 4 & $\begin{array}{l}\text { Pimpinan memberikan } \\
\text { kesempatan berupa promosi } \\
\text { jabatan kepada saya. }\end{array}$ & 0 & 3 & 11 & 18 & 3 & 3,60 & Puas \\
\hline 5 & $\begin{array}{l}\text { Saya diberikan penghargaan } \\
\text { atas prestasi kerja yang saya } \\
\text { raih. }\end{array}$ & 0 & 2 & 9 & 16 & 8 & 3,86 & Puas \\
\hline 6 & $\begin{array}{l}\text { Saya mampu menyelesaikan } \\
\text { tugas sesuai dengan } \\
\text { wewenang jabatan saya di } \\
\text { perusahaan. }\end{array}$ & 0 & 2 & 11 & 20 & 2 & 3,63 & Puas \\
\hline 7 & $\begin{array}{l}\text { Saya mampu menerima } \\
\text { arahan dari pimpinan dan } \\
\text { jabatan yang lebih tinggi. }\end{array}$ & 0 & 3 & 6 & 19 & 7 & 3,86 & Puas \\
\hline & Kepuasan & Kerja & & & & & 3,76 & Puas \\
\hline
\end{tabular}

Dari Tabel 4 dapat disimpulkan variabel kepuasan kerja kerja secara keseluruhan memiliki nilai rata - rata 3,76 yang berarti kepuasan kerja yang dialami pegawai tergolong baik. Hal ini dapat dilihat dari masing - masing nilai indikator yang berada antara nilai interval setuju. Hal ini berarti pekerjaan yang cukup menarik, merasa nyaman bekerja dalam perusahaan, mampu menunjukkan prestasi kerja, kesempatan promosi jabatan, penghargaan atas prestasi kerja, mampu menyelesaikan tugas sesuai wewenang jabatan dan mampu menerima 
arahan dari pimpinan sudah terbilang baik dan perlu adanya perhatian agar bisa ditingkatkan lagi.

Tabel 5 menunjukan skor untuk variabel komitmen adalah sebesar 3,69 ini berarti menyatakan bahwa responden setuju pada variabel komitmen organisasi pada perusahaan PBF. PT. Banyumas. Hal ini dapat diperinci sebagai berikut : senang terlibat dalam organisasi (x.3.1), memiliki perasaan ingin tetap tinggal dalam organisasi (x.3.2), bertanggung jawab melakukan pekerjaan dalam organisasi (x.3.3).

\section{Tabel 5.}

Penilaian Responden pada Variabel Komitmen Organisasi

\begin{tabular}{|c|c|c|c|c|c|c|c|c|}
\hline \multirow[t]{2}{*}{ No } & \multirow[t]{2}{*}{ Pernyataan } & \multicolumn{5}{|c|}{$\begin{array}{c}\text { Proporsi Jawaban } \\
\text { Responden }\end{array}$} & \multirow{2}{*}{$\begin{array}{l}\text { Rata- } \\
\text { Rata }\end{array}$} & \multirow[t]{2}{*}{ Kriteria } \\
\hline & & STS & TS & $\mathbf{N}$ & $\mathbf{S}$ & SS & & \\
\hline 1 & $\begin{array}{l}\text { Saya merasa senang terlibat } \\
\text { dalam organisasi. }\end{array}$ & 1 & 1 & 10 & 19 & 4 & 3,69 & Baik \\
\hline 2 & $\begin{array}{l}\text { Saya ingin tetap tinggal } \\
\text { dalam organisasi. }\end{array}$ & 0 & 4 & 9 & 19 & 3 & 3,60 & Baik \\
\hline 3 & $\begin{array}{l}\text { Saya bertanggung jawab } \\
\text { untuk melakukan pekerjaan di } \\
\text { organisasi. }\end{array}$ & 0 & 3 & 7 & 20 & 5 & 3,77 & Baik \\
\hline & Komitmen & rganisa & & & & & 3,69 & Baik \\
\hline
\end{tabular}

Sumber: Data Diolah, 2017

Analisis data yang dipakai pada penelitian ini adalah hasil analisis regresi linear berganda dengan menggunakan aplikasi SPSS (Statistical Package for Social Science) model ini digunakan untuk mengetahui sejauh mana pengaruh antara variabel dependent (variabel terikat) dengan variabel bebasnya (independent) baik secara simultan maupun parsial (Sugiyono, 2007: 277).

Hasil (output) dari model analisis dari analysis regresi linear berganda yang dimaksud adalah sebagai berikut. 
Tabel 6.

Hasil Analisis Regresi Linear Berganda

\begin{tabular}{|c|c|c|c|c|c|c|c|c|}
\hline \multirow{2}{*}{\multicolumn{2}{|c|}{ Model }} & \multicolumn{2}{|c|}{$\begin{array}{c}\text { Unstandardized } \\
\text { Coefficient }\end{array}$} & \multicolumn{2}{|c|}{$\begin{array}{l}\text { Standardized } \\
\text { Coefficient }\end{array}$} & \multicolumn{3}{|c|}{$\begin{array}{c}\text { Collinearity } \\
\text { Statistic }\end{array}$} \\
\hline & & B & Std. Error & Beta & $\mathrm{t}$ & Sig. & Tolerance & VIF \\
\hline \multirow[t]{3}{*}{1} & (Constant) & .000 & .113 & & .000 & 1.000 & & \\
\hline & Stres Kerja & -.372 & 156 & -.372 & $-2,390$ & .023 & .543 & 1841 \\
\hline & $\begin{array}{l}\text { Kepuasan } \\
\text { Kerja }\end{array}$ & .457 & .156 & .457 & 2,935 & .006 & .543 & 1841 \\
\hline
\end{tabular}

a. Dependent variable : Komitmen Org.

Sumber: Data Diolah, 2017

Pada Tabel 6 dapat dilihat bahwa besarnya R Square adalah 0,578. Hal ini

berarti 57,8 persen komitmen organisasi karyawan PBF. PT. Banyumas dapat dijelaskan oleh variasi variabel stres kerja, kepuasan kerja, sedangkan sisanya sebanyak 42,2 persen disebabkan oleh faktor - faktor lain diluar model.

Pada Tabel 6 dapat dilihat nilai koefisien regresi dari variabel bebas (stres kerja, kepuasan kerja) dan konstanta (komitmen organisasi), maka diperoleh persamaan regresi linear berganda sebagai berikut.

$$
\mathrm{Y}=0.000+0,372(\mathrm{X} 1)+0,457(\mathrm{X} 2)
$$

Berdasarkan persamaan tersebut, maka pengaruh stres kerja dan kepuasan kerja terhadap komitmen organisasi PBF. PT. Banyumas Denpasar dapat diartikan sebagai berikut. Diketahui konstanta besarnya 0,000 mengandung arti jika stres kerja (X1) dan kepuasan kerja (X2) tidak berubah, maka komitmen organisasi (Y) tidak mengalami perubahan. $\beta 1=0,372$; berarti apabila variabel stres kerja $(\mathrm{X} 1)$ meningkat, maka akan mengakibatkan penurunan pada komitmen organisasi (Y), dengan asumsi variabel kepuasan kerja dianggap konstan. $\beta 2=0,457$; berarti apabila variabel kepuasan kerja (X2) meningkat, maka akan mengakibatkan peningkatan pada komitmen organisasi (Y), dengan asumsi variabel stres kerja dianggap konstan. 
Uji Normalitas bertujuan untuk menguji apakah dalam model regresi, variabel residual mempunyai distribusi data normal atau mendekati normal. Metode yang digunakan adalah dengan menggunakan statistik KolmogorovSmirnov test. Kriteria yang digunakan dalam test ini adalah dengan membandingkan antara tingkat signifikansi yang di dapat dengan tingkat alphayang digunakan, dimana data tersebut dikatakan berdistribusi normal bila sig > 0,005 (Ghozali, 2012:141).

Tabel 7.

\section{Hasil Uji Normalitas}

One-Sample Kolmogorov-Smirnov Test

\begin{tabular}{llr}
\hline & & Unstandarized Residual \\
\hline $\mathrm{N}$ & & 35 \\
Normal Parameters & Mean & 0 \\
& Std. Deviation & 0.64961 \\
Most Extreme & Absolute & 0.157 \\
Difference & Positive & 0.103 \\
& Negative & -0.157 \\
Kolmogorov-Smirnov Z & & 0.959 \\
Asymp. Sig. (Tailed) & & 0.354 \\
\hline
\end{tabular}

a. Test distribution is Normal

b. Calculated from Data.

Sumber: Data Diolah, 2017

Tabel 7 menunjukkan bahwa nilai Asymp. Sig sebesar 0,354 > 0,05, sehingga dapat disimpulkan bahwa data terdistribusi dengan normal. Berikut merupakan hasil uji normalitas.

Model regresi yang baik seharusnya tidak terjadi korelasi diantara variabel independent. Untuk menguji apakah terdapat korelasi diantara variabel bebas (independent), maka perlu melakukan uji multikolienaritas (Ghozali, 2012: 105). Tabel 8 menunjukan hasil uji multikolinearitas. 
Tabel 8.

Hasil Uji Multikolinearitas

\begin{tabular}{|c|c|c|c|c|c|c|c|c|}
\hline \multirow{2}{*}{\multicolumn{2}{|c|}{ Model }} & \multicolumn{2}{|c|}{$\begin{array}{l}\text { Unstandardized } \\
\text { Coefficient }\end{array}$} & \multicolumn{2}{|c|}{$\begin{array}{l}\text { Standardized } \\
\text { Coefficient }\end{array}$} & \multicolumn{3}{|c|}{$\begin{array}{c}\text { Collinearity } \\
\text { Statistic }\end{array}$} \\
\hline & & B & Std. Error & Beta & $\mathrm{t}$ & Sig. & Tolerance & VIF \\
\hline \multirow[t]{3}{*}{1} & (Constant) & .000 & .113 & & .000 & 1.000 & & \\
\hline & Stres Kerja & -.372 & .156 & -.372 & $-2,390$ & .023 & .543 & 1841 \\
\hline & $\begin{array}{l}\text { Kepuasan } \\
\text { Kerja }\end{array}$ & .457 & .156 & 457 & 2,935 & .006 & .543 & 1841 \\
\hline
\end{tabular}

a. Dependent variable : Komitmen Org.

Sumber: Data Diolah, 2017

Hasil uji multikolinearitas pada tabel 8 menunjukkan bahwa nilai tolerance variabel bebas berada di atas 0,1 dan nilai VIF berada di bawah 10 . Jadi dapat disimpulkan bahwa model tidak terdapat gejala multikolinearitas.

Uji Heteroskedastisitas untuk melihat apakah dalam model regresi memiliki ketidaksamaan variancedari residual satu pengamatan ke pengamatan lain. Untuk menguji heteroskedastisitas digunakan uji Glejser. Metode uji Glejser dapat digunakan untuk menguji adanya heteroskedastisitas yang dimana tingkat signifikansinya berada di atas 0,05 dapat dinyatakan model tidak heteros (Ghozali, 2012:139). Hasil uji ini dapat dilihat pada tabel 9.

Tabel 9.

Hasil Uji Heteroskedastisitas

\begin{tabular}{llccccc}
\hline \multirow{2}{*}{ Model } & \multicolumn{2}{c}{ Unstandardized Coefficient } & \multicolumn{3}{c}{ Standardized Coefficient } \\
\cline { 3 - 7 } & \multicolumn{1}{c}{ B } & Std. Error & Beta & \multicolumn{1}{c}{ t } & \multicolumn{2}{c}{ Sig. } \\
\hline \multirow{2}{*}{1} & (Constant) & .434 & .081 & & 5.374 & .000 \\
& Stres Kerja & .120 & .111 & .251 & 1.081 & .288 \\
& Kepuasan Kerja & .003 & .111 & .005 & .024 & .981 \\
\hline
\end{tabular}

a. Dependet Variables: Absres

Sumber: Data Diolah, 2017

Dalam Tabel 9 memperlihatkan angka tingkat signifikansi tiap variabel bebas di atas 0,05 sehingga dapat sehingga dapat disimpulkan model regresi tidak mengandung adanya heteroskedastisitas. 
Uji $\mathrm{F}$ bertujuan untuk menguji apakah semua variabel independen yang dimasukkan ke dalam model secara simultan atau bersama - sama mempunyai pengaruh terhadap variabel dependen (Ghozali, 2006).

Signifikansi Tabel ANOVA menunjukkan besarnya angka probabilitas atau signifikansi pada perhitungan ANOVA. Nilai yang tertera digunakan untuk uji kelayanan Model Analisis (dimana sejumlah variabel x mempengaruhi variabel y) dengan ketentuan angka probabilitas yang baik untuk digunakan sebagai model regresi adalah sebagai berikut. Jika nilai sig $<005$ atau $\mathrm{F}$ hitung $>\mathrm{F}$ tabel, maka terdapat pengaruh variabel stres kerja dan kepuasan kerja secara simultan terhadap variabel komitmen organisasi. Jika nilai sig $>0,05$ atau $\mathrm{F}$ hitung $<=\mathrm{F}$ tabel, maka tidak terdapat pengaruh variabel stres kerja dan kepuasan kerja secara simultan terhadap variabel komitmen organisasi.

Tabel 10.

Hasil Uji F

\begin{tabular}{|c|c|c|c|c|c|c|}
\hline \multicolumn{7}{|c|}{ ANOVA $^{b}$} \\
\hline & Model & $\begin{array}{c}\text { Sum of } \\
\text { Squares }\end{array}$ & df & Mean Square & $\mathrm{F}$ & Sig \\
\hline \multirow[t]{3}{*}{1} & Regression & 19.652 & 2 & 9.826 & 21.915 & $.000^{\mathrm{a}}$ \\
\hline & Residual & 14.348 & 32 & 0.448 & & \\
\hline & Total & 34 & 34 & & & \\
\hline
\end{tabular}

a. Predictors: (Constant), Kepuasan Kerja, Stres Kerja

b. Dependent Variable : Komitmen Org.

Sumber: Data Diolah, 2017

Tabel 10 hasil uji anova (UJI F) di atas, diperoleh nilai antar kelompok pembanding $=2$, nilai dalam kelompok penyebut $=32$, pada alfa $=0,05$, maka nilai $\mathrm{F}$ tabelnya adalah $\mathrm{F} 0,05(2,32)=3,29$.

Tabel hasil uji anova (UJI F) menunjukkan hasil $\mathrm{F}$ hitung sebesar 21,915 dengan signifikansi sebesar 0,000. Oleh karena nilai F Sig. Sebesar 0,000 $<0,05$ 
dan nilai $\mathrm{F}$ hitung 21,915 > 3,29, maka Ho ditolak dan $\mathrm{H} 1$ diterima. Hasil ini mempunyai arti bahwa terdapat pengaruh yang signifikan antara variabel stres kerja dan kepuasan kerja secara simultan terhadap variabel komitmen organisasi.

Uji statistik t bertujuan untuk menunjukkan seberapa jauh pengaruh satu variabel bebas secara individual dalam menerangkan variabel terikat. Level of significant yang digunakan adalah 0,05 atau 5 persen. Apabila tingkat signifikansi t lebih kecil dari 0,05 maka $\mathrm{H}_{0}$ ditolak dan $\mathrm{H}_{1}$ diterima.

Berdasarkan Tabel 8 dapat dilihat bahwa nilai signifikasi uji t untuk variabel stres kerja sebesar 0,023 (lebih kecil dari 0,05) dengan nilai beta sebesar $-0,372$ Maka dapat dikatakan bahwa stres kerja berpengaruh negatif dan signifikan terhadap komitmen organisasi, sehingga hipotesis pertama diterima. Oleh karena itu, semakin tinggi stres kerja maka semakin rendah pula komitmen organisasi karyawan.

Berdasarkan Tabel 8 dapat dilihat bahwa nilai signifikasi uji t untuk variabel kepuasan kerja sebesar 0,006 (lebih kecil dari 0,05) dengan nilai beta sebesar 0,457. Maka dapat dikatan bahwa kepuasan kerja berpengaruh positif dan signifikan terhadap komitmen organisasi, sehingga hipotesis kedua diterima. Oleh karena itu, semakin tinggi kepuasan kerja maka semakin tinggi pula komitmen organisasi.

Pembahasan dari hasil pengujian hipotesis penelitian yang telah dilakukan adalah sebagai berikut. Berdasarkan hasil pengujian hipotesis, pengaruh stres kerja terhadap komitmen organisasi dengan hasil (sig. t $0.000<0.05$ ) serta koefisien beta sebesar -372 menunjukan bahwa stres kerja berpengaruh secara 
negatif dan signifikan terhadap komitmen organisasi. Hal ini menunjukkan bahwa semakin buruk stres kerja yang dialami pegawai, maka akan menurunkan komitmen organisasi karyawan PBF. PT. Banyumas Denpasar. Penelitian ini sesuai dengan penelitian yang dilakukan oleh Khatibi et al. (2009), Firth et al. (2004), Velnampy dan Aravinthan (2013) menyatakan ada hubungan negatif antara stres kerja dengan komitmen organisasional, pegawai yang memiliki tingkat stres tinggi berimplikasi terhadap rendahnya komitmen organisasional mereka.

Berdasarkan hasil pengujian hipotesis, pengaruh kepuasan kerja terhadap komitmen organisasi dengan hasil (sig. t $0.000<0.05$ ) serta koefisien beta sebesar 0,457 menunjukan bahwa kepuasan kerja berpengaruh secara positif dan signifikan terhadap komitmen organisasi. Hal ini menunjukkan bahwa semakin tinggi stres kerja yang dialami pegawai, maka akan menaikkan komitmen organisasi karyawan PBF. PT. Banyumas Denpasar. Penelitian ini sesuai dengan penelitian yang dilakukan oleh Koh dan Bo (2004), Eslami dan Gharakhani (2012), Lumley (2011), Oyewobi et al. (2012) meyatakan bahwa kepuasan kerja berpengaruh positif dan signifikan terhadap komitmen organisasi.

\section{SIMPULAN DAN SARAN}

Berdasarkan hasil penelitian dan pembahasan pada penelitian ini, maka dapat disimpulkan dari penelitian ini adalah Stres kerja berpengaruh negatif dan signifikan terhadap komitmen organisasi di PT. Banyumas Denpasar. Hal ini menunjukkan bahwa semakin tinggi stres kerja yang di alami karyawan, maka akan semakin menurunkan komitmen organisasi karyawan. Kepuasan kerja 
berpengaruh positif dan signifikan terhadap komitmen organisasi karyawan di PT. Banyumas Denpasar. Hal ini menunjukkan bahwa semakin kepuasan kerja karyawan, maka akan semakin tinggi pula komitmen kerja karyawan.

Adapun saran yang dapat diberikan peneliti adalah Berdasarkan indikator stres kerja yang memiliki nilai rata - rata tertinggi adalah tuntutan pekerjaan saya tidak sesuai dengan kemampuan dalam menyelesaikan tugas, sebaiknya perusahaan melakukan survey apakah karyawan sudah mampu dalam menyelesaikan tugas dalam perusahaan. Apabila belum, perusahaan bisa melakukan rolling jabatan sesuai dengan kemampuan karyawan pada bidangnya masing - masing. Perusahaan diharapkan memperhatikan kepuasan kerja karyawan PBF. PT. Banyumas. Berdasarkan indikator kepuasan kerja yang memiliki rata-rata terendah dalam kepuasan kerja adalah Saya merasa pekerjaan yang saya lakukan sangat menarik, sebaiknya perusahaan memberikan variasi pekerjaan lain dari setiap bidang pekerjaan, agar pekerjaan tidak terlalu monoton karena akan menyebabkan karyawan merasa cepat bosan dan menyebabkan stres dalam melakukan pekerjaannya.

\section{REFERENSI}

Adekola, Bola. 2012. The impact of organizational commitment on job satisfaction: a study of employees at nigerian universities. International Journal of Human Resource Studies. 2 (2). pp : 2126-3058.

Amin, Rashidah Mohamad I.A. dan Saleh Munir. 2014. The link between leadermember exchange, organizational citizenship behavior and job satisfaction: a case study on local government. International Journal of Academic Research in Business and Social Science, 4 (5). pp : 2222 6990. 
Cha, Jae Min., Seung Hyun Kim., Ronald F Cichy. 2011. Job Satisfaction, Organizational Commitment, and Contextual Performance: Examining Effects of Work Status and Emotional Intelligence among Private Club Staff Members. Journal of Psychology \& Marketing, 21 (6). pp: 405-424.

Cicei, C.C. 2012. Occupational stress and organizational commitment in Romanian public organizations. Procedia - Social and Behavioral Sciences. 33, pp : $1077-1081$.

Dana Pramitha, Gede., I Wayan Gede Supartha., I Gede Riana. 2012. Pengaruh kepuasan kerja terhadap komitmen organisasional dan kinerja karyawan koperasi krama bali. E-jurnal Manajemen Unud, 1 (2). pp : 191-206.

Divara, I Gusti Agung Gede Krisna., Agoes Ganesha Rahyuda. 2016. Pengaruh work family conflict terhadap stres kerja dan komitmen organisasional pegawai kontrak dinas kebudayaan provinsi bali. E-Jurnal Manajemen Unud. 5 (11). Hal : 6994-7021.

Dockel, Andreas. 2006. The effect of retention factors on organizational commitment: an investigation of high technology employee. SA Journal of Human Resource Management. 4 (28). pp: 20-28.

Durkin, Mark. 1999. Employee commitment in retail banking: identifying and exploring hidden dangers. International Journal of Bank Marketing. 17 (3). pp: 124-134.

Eslami, Javad., Davood Gharakhani. 2012. Organizational Commitment and Job Satisfaction. ARPN Journal of Science and Technology. 2 (2). pp. 225-247.

Firth, Lucy., David J Mellor., Kathleen A Moore., Claude Loquet. 2004. How Can Managers Reduce Employee Intention to Quit?. Journal of Managerial Psychology. 19 (2). pp : 170 - 187.

Gayathiri, R. Ramakrishnan L. 2014. Quality of Work Life - Linkage with Job Satisfaction and Performance. International Journal of Business and Management Invention. 2 (1). pp: 1-8.

Gunlu, Ebru., Mehmet Aksarayli., Nilufer Sahin Percin. 2010. Job Satisfactionand Organizational Commitment of Hotel Managers in Turkey. International Journal of Contemporary Hospitality Management. 22 (5). pp: 693-717.

Hartono, Brian., Roy Setiawan. 2013. Pengaruh komitmen organisasional terhadap kepuasan kerja karyawan paparons pizza city of tommorow. AGORA Jurnal. 1 (1). pp : 1-8.

Hasibuan, S.P. Melayu. 2014. Manajemen Sumber Daya Manusia. Edisi Revisi. Jakarta: Bumi Aksara. 
Hlatywayo, C. K..Mlanga., Tatenda Shaleen., Zingwe T. 2014. Precursors of emotional stability, stress and work-family conflict among female bank employees. International Business \& Economics Research Journal. 13 (4). pp :861-866.

Humala, Roziq. 2014. Kepemimpinan transformasional dengan komitmen organisasi karyawan. Jurnal Ilmiah Psikologi Terapan. 2 (2). Hal: 228240.

Indra Setiawan, Ahmad., Eko Darminto. 2013. Pengaruh dukungan sosial terhadap stres kerja pada karyawan. Jurnal Mahasiswa Psikologi. 1 (3). Hal : 2-4.

Iresa, Amalia Rahma., Hamidah Nayati Utami., Arik Prasetya. Pengaruh konflik kerja dan stres kerja terhadap komitmen organisasional dan kinerja karyawan (studi pada karyawan pt. telekomunikasi indonesia, tbk witel malang). Jurnal Administrasi Bisnis (JAB). 23 (1). Hal : 1-10.

Khatibi, A. H. Asadi., M. Hamidi. 2009. The relationship between job stress and organizational commitment in national olympic and Paralympic academy. World Journal of Sport Sciences. 2 (4). pp : 272-278.

Kreitner, Robert., Angelo Kinicki. 2003. Perilaku Organisasi. Jakarta: Salemba Empat.

Kuo, Tsung-Hsien., Li-AnHo., Chinho Lin., Kuei-Kuei Lai. 2010. Employee empowerment in a technology advanced work environtment. Industrial Management \& Data Systems. 110 (1). pp.24-42.

Koh, Hian Chye., Boo El'fred H.Y. 2004. Organizational ethics and employee satisfaction and commitment. Management Decision. 42 (4). pp: 677-693.

Lumley, E.J. M Coetzee., R Tladinyane., N Ferreira. 2011. Exploring the jobsatisfaction and organisational commitment of employees in the information technology environment Outhern. African Business Review. 15 (1). pp : 889-978.

Mathis, L. Robert., Jackson M John. 2012. Human Resources Management. Jakarta: Salemba Empat.

Meyer, John P., Natalie J. Allen. 1991. A three-component conceptualization of organizational commitment. Human Resource Management Review. 1 (1). pp. 61-89. 
Meyer, John P., Herscovith L. 2001. Commitment in the workplace : toward general model. Human Resource Management Review. 11 (1). pp: 299326.

Moncrief, W.C., E. Cravens Babakus D.W. Johnston M. 1997. Examining the antecedents and consequences of salesperson job stress. Eurupeon Journal of Marketing. 31 (11). pp. 756-798.

Naderi Anari, Nahid. 2012. Teachers: emotional intelligence, job satisfaction, and organizational commitment. Journal Workplace Learning. 24 (4). pp 256 269.

Naqvi, S.M.M.R. Maria Ishtiaq. NousheenKanwaldanMohsin Ali. 2013. Impact on job autonomy on organizational commitment and job satisfaction: the moderating role of organizational culture in fast food sector of pakistan. International Journal of Business and Management. 8 (17). pp: 92-102.

Nata Wirawan, I Gusti Putu. 2002. Cara Mudah Memahami Statistik 2 (Statistik Inferensia) untuk ekonomi dan bisnis. edisi kedua. Denpasar : Keraras Emas.

Oshagbemi, T. 1997. Job Satisfaction and Dissatisfaction in Higher Education. Education \& Training. 39 (9). pp: 354-359.

Oyewobi, Luqman Oyekunle., Bolaji Suleiman., Abubakar Muhammad-Jamil. 2012. Job satisfaction and job commitment : a study of quantity surveyors in nigerian public service. International Journal of Business and Management. 7 (5). pp: 179-192.

Panggabean, Mutiara Sibarani. 2004. Komitmen organisasi sebagai mediator variabel bagi pengaruh kepuasan kerja terhadap keinginan untuk pindah kerja. Jurnal Bisnis dan Akuntansi. 6 (1). Hal. 90-114.

Pool, S . W. 2000. Organizational Culture and its relationship between Job Tension in measuring outcomes Among Business Executive. The Journal Of Management Development. 19 (1). pp: 32-49.

Pradhiptya, A R. 2013. Pengaruh kepuasan kerja terhadap organizational citizenship behavior (OCB) dengan mediasi komitmen organisasional. Jurnal Ilmu Manajemen. 1 (1). Hal: 342-352.

Probotranggono, Rahadian., Andi Kartika. 2008. Pengaruh komitmen organisasional dan profesional terhadap kepuasan kerja auditor dengan motivasi sebagai variabel intervening. Jurnal Bisnis dan Ekonomi. 15 (1). Hal. $80-90$. 
Puspitawati, Ni Made Dwidan.,I Gede Riana. 2014. Pengaruh kepuasan kerja terhadap komitmen organisasional dan kualitas layanan. Jurnal Manajemen Strategi Bisnis dan Kewirausahaan. 8 (1). Hal. 68-80.

Ramayah, T. Aizzat Mohd Nasurdin. 2003. Job satisfaction and organizational commitment: differential effects ror men and women. Jurnal Manajemen dan Bisnis. 5 (1). Hal. 75-90.

Rehman, Muttieur., Rabbia Irum., Namra Tahir., Zara Ijaz., Uzma Noor., Ume Salma. 2012. The impact of job stress on employee job satisfaction: a study on private colleges of pakistan. Journal of Business Studies Quarterly. 3 (3). pp. 50-56.

Richardson, Katherine M., Hannah R. Rothstein. 2008. Effect of occupational stress management intervention programs: A meta-analysis. Journal of Occupational Health Psycology. 13 (1). pp. 63-93.

Roelen, C.A.M., 2008. Which work factors determine job Satisfaction. International Journal of Industrial Ergonomics. 30 (4). pp: 433-439.

R. W. Rowden. 2000. The relationship between charismatic leadership behaviors and organizational commitment. Leadership \& Organization Development Journal. 21 (1). pp. 30-35.

Shurbagi, Adel. 2014. The relationship between transformational leadership style, job satisfaction and the effect of organizational commitment. International Business Research. 7 (11). pp: 1913-9004

Silva, Paula. 2006. Effects of Disposition on Hospitality Employee Job Satisfaction and Commitment. International Journal of Contemporary Hospitality Management. 18 (4). pp: 317 - 328.

Sugiyono. 2014. Metode Penelitian Pendidikan Pendekatan Kuantitatif, Kualitatif dan $R \& D$. Bandung: Alfabeta

Syahronica, Gabriela., Moehammad Soe'oed Hakam., Ikana Ruhana. 2015. Pengaruh kepuasan kerja dan stres kerja terhadap turnover intention (studi pada karyawan departemen dunia fantasi PT. Pembangunan Jaya Ancol, Tbk). Jurnal Administrasi Bisnis (JAB). 20 (1). Hal: 1-6.

Tania, A. Eddy M. Sutanto. 2013. Pengaruh motivasi kerja dan kepuasan kerja terhadap komitmen organisasional karyawan PT. Dai Knife di Surabaya. Agora. 1 (3). Hal: 1702-1720. 
Teck-Hong. T. Waheed, A. 2011. Herzberg's motivation-hygiene theory and job satisfaction in the malaysian retail sector: The mediating effect of love of money. Asian Academy of Management Journal. 16 (1). pp: 73-94.

Umar, Husein. 2008. Desain Penelitian Akuntansi Keperilakuan. Jakarta : PT Raja Grafindo Persada.

Uppal, N., Mishra S.K., Vohra N. 2014. Prior related work experience and job performance: role of personality. International Journal of Selection and Assessment. 22 (1). pp: 39-51.

Velnampy, $\mathrm{T}$ and Aravinthan. S. A. 2013. Occupational stress and organizationalcommitment in private banks: a srilankan experience. European Journal of Business and Management. 5 (7). pp: 78-99.

Widyanti, Rahmi., Armanu Thoyib., Heru Susilo. 2004. Faktor-faktor pengembangan karier yang mempengaruhi kepuasan kerja serta pengaruhnya terhadap komitmen karyawan pada organisasi. Jurnal Aplikasi Manajemen. 2 (1). Hal : 33-47.

Wibowo, I Gede Putro., Gede Riana., Made Surya Putra. 2015. Pengaruh Stres Kerja Terhadap Kepuasan Kerja dan Komitmen Organisasional Karyawan. E-Jurnal Manajemen Unud. 4 (2). pp. 125-145.

Wirawan, Nata. 2002. Statistik Deskriptif. Edisi ke 2. Bali: Keraras Emas

Yahaya, Noordin., Azizi Yahaya., Farhana Amat Tamyes., Jasmi Ismail., Saini Jaalam. 2010. The effect of various modes of occupational stress, job satisfaction, intention to leave and abseentism companies commission of malaysia. Australian Journal of Basic and Applied Sciences. 4 (7). pp: 1676-1679.

Yousef, Darwis. A. 2002. Job satisfaction as a mediator of the relationship between role stressor and organizational commitment: a study from an Arabic Cultural Perspective. Journal of Management Psycology. 17 (4). pp: 250-266. 